\section{Sir Alan Cottrell Receives Von Hippel Award}

The Materials Research Society's highest honor, the Von Hippel Award, this year will be given to Sir Alan Cottrell, honorable distinguished research fellow in the Department of Materials Science and Metallurgy, Cambridge University. $\mathrm{He}$ was cited for "converting crystal dislocations from a handwaving hypothesis to a rigorous discipline, transforming the understanding of brittle fracture, making varied and crucial advances in the theory of radiation damage, and for transforming the teaching of materials science throughout the academic world through his pioneering textbooks." The Von Hippel Award is given annually to an individual in recognition of outstanding contributions to interdisciplinary research on materials.

Sir Alan's earliest research was in solidly practical metallurgy related to welding, work hardening, and precipitation hardening, areas where he always displayed a fine understanding of the fundamentals of physics and chemistry. When both the importance and detailed properties of dislocations began to be appreciated just after World War II, he was among the first to relate theoretical concepts to real problems. One of his many important contributions was to demonstrate that the existence of an upper yield point in steel is linked to the trapping of dislocations by mobile interstitial carbon atoms-an elegant example of his ability to relate old problems to new ideas with precision and clarity.

Later he turned his talents to a combination of practical and experimental problems associated with materials that have been subjected to heavy neutron irradiation, such as in a nuclear reactor. Earlier this year he was presented with an honorary degree by Cambridge University, "There are two particular reasons why we should all be grateful to him. The first concerns the installation of uranium rods in a reactor: he perceived that when they were lowered into their containers and subjected to irradiation, they would not keep shape but would grow in length and begin to bend; he inspired the design of a frame which saved the situation. Second, he made inquiries about the safety of the containers in the reactor; they told him that the walls were sound, and he asked if they had proved it: hence the cunning use of ultrasound to search for cracks within the walls themselves. Thus he has earned the thanks not only of scientists and the nuclear industry, but also

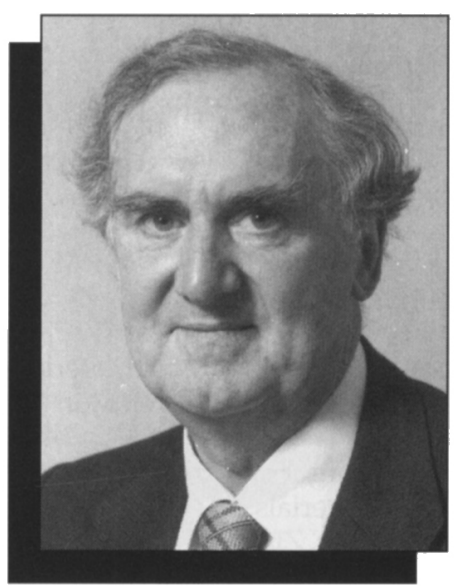

of the whole country." His expertise on the fracture mechanics of reactor pressure vessels, linked to his knowledge of radiation embrittlement, has been valuable to designers of nuclear reactors for many years.

In an era when the mechanical properties of steel belonged to mechanical engineers, particularly fracture potential and shaping for manufacture, radiation damage was studied by physicists. Sir Alan's pioneering work in the 1950s and 1960s on the theory of yield point, strain-aging, and brittle fracture led to an enduring link in the way engineers and metallurgists study and control these forms of behavior. His elegant studies of topics such as radiation embrittlement and radiation-enhanced creep brought the perspective of a brilliant metallurgist to a field that had previously been dominated by solid-state physicists, leading to long-term interactive research by the two professions. The shaping of steel sheet, in particular, is profoundly affected by discontinuous yield, and Sir Alan's studies had substantial effects on industrial practices.

Sir Alan is held in high esteem by industrialists, as evidenced by his many advisory appointments and invited lectures on issues of applied science and public policy. He has been influential for many years as an expert advisor in fracture mechanics, radiation damage, intermetallics (as an advisor to Rolls Royce), and even as a director of a major British company (Fisons).

In his classic book, Theoretical Structural Metallurgy, Sir Alan was the first to bring modern statistical mechanics to the education of metallurgists, in addition to bringing dislocation theory and the electron theory of metals and alloys. His books have been profoundly influential in educating generations of diverse materials scientists. Some of his papers have established links to inorganic chemistry, especially his active interest in what constitutes a metal and in the metal-insulator transition.

Sir Alan Cottrell is one of the most honored materials scientists. He was knighted by Queen Elizabeth in 1971, and is a fellow of both the Royal Society and the Royal Academy of Engineering. He has received 16 honorary degrees and an even greater number of medals and awards from professional societies and other organizations around the world. He has written 11 books, including several classics, and more than 160 scientific papers.

Sir Alan received his BSc degree in 1939 from the University of Birmingham, followed by a PhD degree in 1942 . He was a lecturer in metallurgy at the University of Birmingham from 1943 to 1949, professor from 1949 to 1955 , followed by three years as deputy head of the Metallurgy Division of the Atomic Energy Research Establishment. His posts at Cambridge University include Goldsmiths' professor of metallurgy (1958-1965), Fellow of Christ's College (1958-1970), Master of Jesus College (1974-1986), and vice-chancellor (1977-1979). As Master of Jesus College, he introduced its first female students.

He held a number of scientific advisory posts with the British government, including deputy chief and chief scientific advisor (studies) to the Ministry of Defense, deputy and later chief scientific advisor to Her Majesty's government, and numerous other scientific advisory posts. He is a foreign honorary member of the American Academy of Arts and Sciences, a foreign associate of the National Academy of Sciences and the National Academy of Engineering, and a fellow of ASM International and the Royal Swedish Academy of Sciences.

Sir Alan has also been chosen to receive the Copley Medal this year, which is the highest award that the Royal Society in London can bestow.

Sir Alan Cottrell will present his talk, "The Art of Simplification in Materials Science," on Wednesday, December 4 after the awards ceremony at 6:00 p.m. in Salon E, Marriott Hotel. 